Д.В. Прочухан

Харківський комп'ютерно-технологічний фаховий коледж

Національного технічного університету “Харківський політехнічний інститут”, Харків

\title{
РЕАЛІЗАЦІЯ ДОДАТКУ ПРОВЕДЕННЯ АНКЕТУВАННЯ ЧЛЕНІВ ПРОЕКТНИХ КОМАНД
}

Розглянуто актуальну проблему забезпечення ефективного механізму анкетування членів проектних команд. В результаті проведеного аналізу публікацій обгрунтовано створення веб-додатку у якості програмного забезпечення для розв'язання наведеної задачі. Програмне забезпечення повинно усувати недоліки аналогів: неефективний контроль введення інформаџії, відсутність гнучкої локалізачії, збереження результатів у незручному форматі. Для реалізації додатку обрано засоби розробки HTML, CSS, Javascript. Для зберігання результатів використано систему керування базами даних Firebase. Адаптивність розробленого додатку надає можливість користувачам проходити анкетування на різних типах пристроїв, переглядати підсумки опитування, а адміністраторам - проводити аналіз отриманої інформаџї, здійснювати наламтування зовнішнього вигляду анкети: редагувати параметри і зміст питань, додавати нові питання $і$ видаляти неактуальні. Реалізовано окрему сторінку для перегляду бази даних анкет і підсумків опитування, на якій за рахунок програмного стискання інформаиї забезпечується зручний перегляд для користувача. Передбачено контроль введення числових покажчиків, обов 'язковий вибір однієї правильної відповіді у відповідних питаннях, щз надає розробленому додатку переваги над аналогами. Програмний код оптимізовано для забезпечення мінімального часу завантаження додатку - 0.9 с. Забезпечено можливість подальшої локалізачії додатку за рахунок використання JSON-формату. Працездатність програмного додатку перевірена з використанням різної апаратної і програмної конфігурації. Розроблений додаток може бути використаний для проведення анкетування членів проектних команд, збору параметрів оцінювання проектів, колекціонування, обробки результатів, застосування в програмному забезпеченні “РМ Guіdе”. Гнучкість архітектури і програмного коду надає можливості використовувати застосунок для проведення інших видів опитування в проектному менеджменті.

Ключові слова: анкетування, опитування, проєктний менеджмент, вибір методологї.

\section{Вступ}

Постановка проблеми. Розвиток проектного менеджменту сприяє появі великої кількості методологій і стандартів. У зв'язку з цим для менеджерів та інших членів команд актуальним $є$ питання вибору певної методології для нового проекту або групи проектів. Вказане питання також постає при вдосконаленні бізнес-процесів в компанії. Невірний вибір методології для нових може привести до великої втрати коштів, зриву строку кінцевого випуску, а для існуючого проекту - до недостатнього розвитку і гальмування темпів зростання. Доцільний вибір методології навпаки призводить до успішного виконання проекту у визначений термін, покращення і оптимізації бізнес-процесів існуючого проекту. Наразі доцільно проводити оцінювання параметрів методом анкетування. Паперові опитувальні листи є застарілим і неефективним методом опитування. Тому актуальною задачею $є$ розробка додатку, що дозволить проводити анкетування для подальшого оцінювання параметрів проекту в електронній формі, автоматично формувати результати опитування в зручному вигля- ді, зберігати отримані дані для аналізу і подальшої обробки.

Аналіз останніх досліджень і публікацій. В проєктному менеджменті анкетування $є$ ефективним та надійним методом для отримання даних, аналізу i використання отриманих результатів для покращення бізнес-процесів. Доцільність використання опитування було висвітлено у низці наукових досліджень. В роботі [1] завдяки опитуванню 21 менеджера було виявлено переваги використання методології Agile для поліпшення результатів розробки і задоволення потреб клієнтів. В дослідженні [2] було поставлено мету виявити переваги і недоліки впровадження Agile. В результаті опитування, яке охопило 120 різних компаній з 35 різних країн, було виявлено, що простота впровадження $є$ найбільш задовільним фактором впровадження Agile, а найменш задовільним - слабка інтеграція з іншими системами. Ефективний механізм використання анкетування також було висвітлено у роботах [3-8].

За допомогою оцінювання параметрів опитування і подальшої обробки можна робити висновки щодо використання певної методології. В дослі- 
дженні [9] було проведено анкетування 197 фахівців індустрії комунікаційних послуг Пакістану та виявлено позитивний вплив Agile на успіх проектів. В роботі [10] запропоновано метод і математичну модель синтезу методології управління з урахуванням нечіткості вихідних даних проекту. У наведеному методі запропоновано анкету з 23 питаннями, що стосуються кількості залучених людей, досвіду роботи замовника 3 командою, оцінки компетентності команди менеджером, ймовірності появи ризикових подій та інші критерії оцінювання параметрів проекту. За результатами опитування розраховуються зважені відстані Евкліда і Геммінга від розглянутого проекту до кожного з підходів. На основі обчислення обирається одна з семи альтернатив (РMBOK, PRINCE2, ISO21500, SWEBOK, SCRUM, XP i KANBAN), для якої вказані відстані є мінімальними. В дослідженні [11] побудовано математичну модель синтезу методології управління проектом та його оточення 3 урахуванням нечіткості вихідних даних для проекту створення програмного забезпечення. В роботі [12] висвітлено розробку програмного забезпечення “PM Guide” для розв'язку задачі вибору методології управління проектом на основі методу, запропонованому в дослідженні [10]. Для опитування членів проектних команд в електронному вигляді можна використовувати три основних способи анкетування: опитування на комп'ютері, опитування по електронній пошті та веб-опитування. Опитування на комп'ютері можна проводити на одному комп'ютері організації, за допомогою локальної мережі або користуватися диском 3 програмним забезпеченням анкетування, а потім зберігати відповіді респондентів на ньому [13]. Ці способи мають наступні недоліки: великі матеріальні витрати для невеликої групи людей, несумісність програмного забезпечення. При використанні анкетування по електронній пошті можуть виникати такі складнощі: можливість випадкового видалення листа, перевантаження поштової скриньки та інші. Веб-опитування усувають частину наведених недоліків [13]. Для створення анкети можна використовувати низку онлайн-сервісів. Найбільшу популярність має Google Forms. Переваги вказаного сервісу: велика кількість вбудованих анкет, можливість створення різних типів питань. Недоліки Google Forms: слабкі можливості контролю введення інформації, перегляд підсумкових результатів здійснюється за допомогою Excel, що може призвести до проблем сумісності, для локалізації потрібно створювати нові форми. Розглянемо ще низку сервісів для проведення опитування. Survey Monkey, Survio, Simpoll i Anketolog мають переваги, аналогічні до Google Forms. До значних недоліків слід віднести обмеження в безкоштовних версіях. В безкоштовних версіях Survey Monkey i Survio можна створювати лише до 10 питань, а проходити одночасне анкетування можуть лише 100 респондентів. В безкоштовній версії сервісу Simpoll обмеження наступні: 3 опитування по 10 питань. В безкоштовній версії сервісу Anketolog можна створювати лише 3 опитування по 10 питань для 50 респондентів. Зважаючи на певні недоліки Google Forms і обмеження інших онлайн-сервісів актуальною задачею є розробка безкоштовного додатку "Survey", який усуне вказані недосконалості та стане зручним засобом опитування для збору даних та подальшої їх обробки такими програмними засобами як "PM Guide".

Мета статті - розробка ефективного механізму реалізації анкетування членів проектних команд на основі методу і математичної моделі, запропонованими в роботі [10], підвищення ефективності опитування за рахунок забезпечення можливості для респондента відповідати на питання на мобільному телефоні, здійснення функцій контролю введення даних, відображення відповідей, обчислення попередніх результатів, збору параметрів оцінювання параметрів проектів, колекціонування у зручному вигляді та подальшої обробки отриманих даних.

\section{Виклад основного матеріалу}

Для розробки додатку використаємо математичну модель, розглянуту в дослідженні [10]. В нашому додатку слід передбачити 2 типи користувачів. Респонденти, члени проектних команд виконують ролі користувачів додатку та повинні мати доступ до проходження анкетування, перегляду результатів. Менеджерам необхідно надати адміністративні ролі: забезпечити можливості редагування, додавання, видалення, змінювання питань анкети.

Для користувачів-респондентів додатку потрібно забезпечити наступні функції: можливість проходити опитування на різних пристроях (ПК, мобільний телефон і т.д), реалізацію механізму вибору однієї відповіді із запропонованих для питань анкети під номерами $1-2 ; 6-7 ; 9-18 ; 20-23$ та контроль обов'язкового вибору однієї відповіді, введення числового покажчика від 0 до 1 для питань 3-5; 8; 19 в кожному полі та забезпечення контролю для кожного 3 варіантів відповідей, забезпечення перевірки обов'язкового введення назви проекту і назви анкети, формування підсумкових результатів поточного опитування, відображення результатів анкетування за всіма анкетами на окремій сторінці в масштабованому вигляді, збереження результатів в базі даних.

Адміністратор-менеджер наслідує всі функції користувача і повинен мати наступні додаткові можливості: редагування, видалення, додавання питань, зміна змісту і зовнішнього вигляду питань анкети за потреби.

Для розробки додатку було використано сучас- 
ні засоби програмування. Мова гіпертекстової розмітки документів HTML і каскадні таблиці стилів CSS були застосовані для створення інтерфейсу додатку. Мову Javascript використано для розробки скриптів обробки інформації. Питання анкети зберігаються в файлі у форматі JSON. Для збереження і обробки результатів анкетування використано об'єктно-орієнтовану систему керування базами даних (СКБД) Firebase. В цій СКБД результати зберігаються у вигляді ієрархічної структури.

Кожна гілка містить повну інформацію про певну анкету. На рис. 1 наведено діаграму розгортання для додатку.

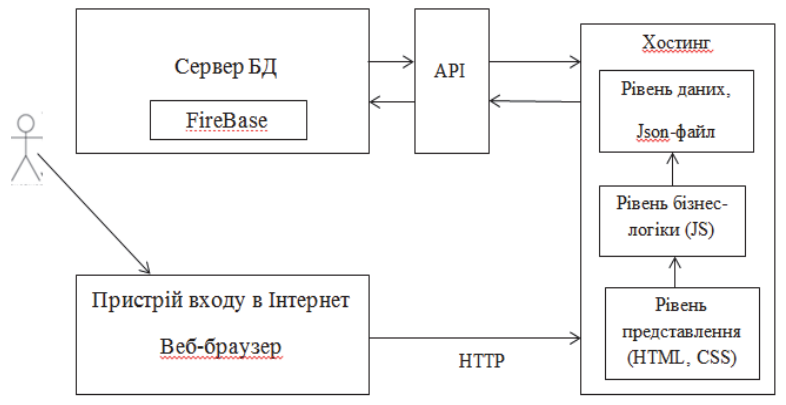

Рис. 1. Діаграма розгортання додатку Джерело: розроблено автором.

На наведеній діаграмі продемонстровано, як відбувається процес використання додатку. Застосунок представлений у вигляді трирівневої архітектури. На рівні представлення завантажується інтерфейс сторінки анкетування засобами HTML та CSS. Користувач повинен відкрити додаток за допомогою пристрою входу в Інтернет у веб-браузері. Документ HTML оброблюється браузером та відтворюється на екрані у звичному для людини вигляді. Для привабливого оформлення інтерфейсу додатку використано мову CSS. Також за допомогою CSS у додатку зроблені кольорові керуючи елементи головної сторінки та масштабування сторінки анкет. Рівень бізнес-логіки реалізований за допомогою Javascript. Сценарії Javascript надають можливість на стороні клієнта керувати браузером, асинхронно обмінюватися даними з сервером, змінювати структуру та зовнішній вигляд веб-сторінки. Рівень даних представлений форматом JSON. Формат JSON буде використано для передачі структурованої інформації через мережу за протоколом ТСР. 3 пристрою клієнта надходить сигнал до АРI, яке звертається до СКБД Firebase, беручи інформацію та надсилаючи іiі в обробленому вигляді назад до користувача. Клієнт має можливість користуватися веб-застосунком після надходження даних. База даних змінюється в реальному часі. Будь-які зміни відразу синхронізуються між усіма клієнтами і приладами, які використовують одну і ту ж базу даних. Оновлення в базі да- них відбуваються миттєво.

Перелічимо структурні компоненти розробленого додатку. Index.html - сторінка анкетування (головна) з питаннями, яка завантажується одразу після запуску застосування. Data.json - файл з питаннями анкети, який може бути легко змінено. Script.js сценарій обробки результатів анкетування згідно математичної моделі, запропонованої в роботі [10]. Results.html - сторінка відображення анкет 3 підсумковими результатами. Table.js - сценарій відображення анкет у масштабованому вигляді і підбиттям підсумків. Auth.hlml - форма входу для адміністратора. Editquestions.html - сторінка редагування питань анкети. Проілюструємо результати розробки додатку. Після успішного завантаження головної сторінки користувачу необхідно в текстових полях, що показані на рис. 2, ввести назву проекту и назву продукту

Project evaluation

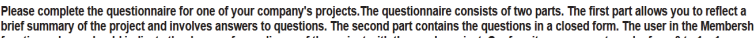

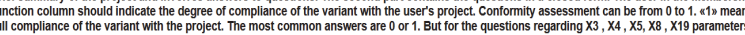
chill complance o t the variant with
this may be a score between 0 and

Project name

Рис. 2. Текстові поля для введення назви проекту i продукту у незаповненому вигляді Джерело: розроблено автором.

Якщо поля не заповнені, то вони залишаються поміченими червоним кольором, повідомляючи користувача про необхідність введення цієї операції. Якщо відбулося коректне введення інформації, червоний колір деактивується і змінюється на чорний, а введена інформація передається для подальшої обробки. Згідно роботи [10] для питань під номерами $3,4,5,8,19$ анкети реалізовано введення числового покажчика в діапазоні від 0 до 1 для певного чинника. Користувач може ввести число 3 клавіатури або з використанням миші і стрілки справа.

Для допомоги при введенні відповідей у додатку реалізовано підказки в полях введення, а також можливість ввести покажчик, клацнувши мишею. У випадку некоректного введення числового покажчика, що виходить за контрольний діапазон, поле підсвічується червоним кольором.

На рис. 3 представлена відповідь на питання № 5 анкетування, під час якої користувач зробив некоректне введення чотирьох коефіцієнтів.

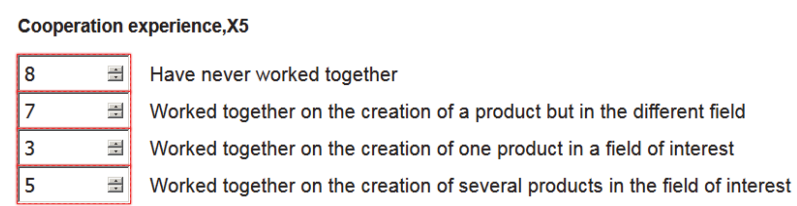

Рис. 3. Маркування некоректної відповіді користувача червоним кольором Джерело: розроблено автором. 
Вигляд питання 3 коректними введенням покажчиків представлено на рис. 4.

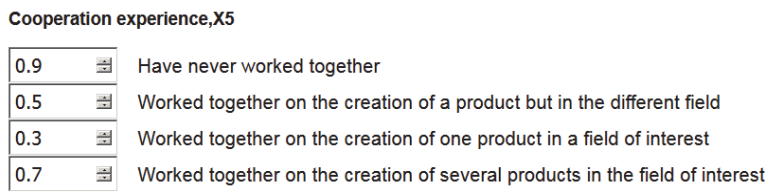

Рис. 4. Коректна відповідь на питання анкети 3 введенням числових покажчиків Джерело: розроблено автором.

Після проходження анкетування і натиснення кнопки “Get Result" користувач, що коректно відповів на всі питання, має можливість отримати результати проходження поточного анкетування, які відображаються під цією кнопкою. Приклад результату проходження анкетування представлено на рис. 5 .

\section{Get result}

\section{$1: 8.76$ \\ 2: 6.56 \\ 3: 5.3 \\ 4: 2.2}

Рис. 5. Результат проходження анкетування Джерело: розроблено автором.

Для перегляду результатів опитування за всіма анкетами створена окрема сторінка, перейти на яку можна, натиснувши посилання “All Results” на головній сторінці. Користувач має можливість передивитися результатів опитування за всіма анкетами 3 відповідями і підсумками на окремій сторінці, на якій назви анкет відображаються у стовпчиках, а результати - в рядках. У разі великої кількості анкет відбувається масштабування інформації. На рис. 6 представлений фрагмент сторінки бази 8 анкет, що містить інформацію про відповіді на 3 питання.

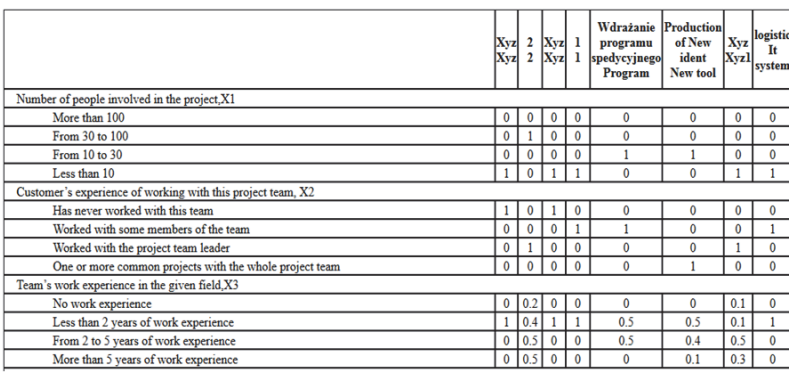

Рис. 6. Фрагмент сторінки з підсумками Джерело: розроблено автором.

Для редагування анкети в додатку “Survey” було розроблено режим адміністратора. На рис. 7 представлено фрагмент сторінки редагування анкет.

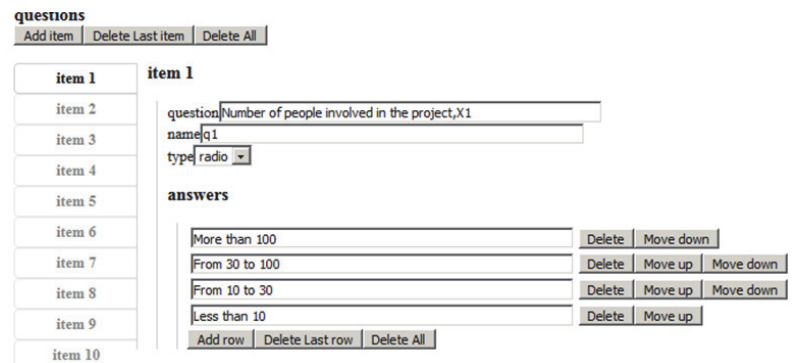

Рис. 7. Фрагмент сторінки керування Джерело: розроблено автором.

Після проходження процедури авторизації адміністратор отримує доступ до функцій керування зовнішнім виглядом сторінки анкетування і змісту анкет. Для додавання нового питання в анкету слід натиснути кнопку “Add Item”. У полі “tуре” обирається тип питання анкети: тип "radio" - питання 3 вибором одного варіанту відповіді, тип "text" - питання 3 введенням числового покажчика впливу певного чинника. Кнопка “Add row" призначена для додавання варіантів відповіді питання. Кнопка "Delete last row" призначена для видалення останнього варіанту. Кнопка "Delete ALL" призначена для видалення всіх відповідей. Для переміщення відповідей в межах одного питання призначені кнопки Move down" i "Move Up” призначенні відповідно для переміщення питань анкети вниз і вгору. У лівій частині режиму адміністратора представлений список номерів питань. Для редагування питання потрібно обрати відповідне питання, клацнувши по його назві і ввести зміни. Для видалення певного питання слід скористатися кнопкою "Delete last item”. Таким чином, редагування анкети дозволяє використовувати застосунок для створення інших видів анкетування з проектного менеджменту.

\section{Висновки}

Розроблено додаток для проведення анкетування членів проектних команд. Наведено основні компоненти веб-додатку та схема його функціонування. Працездатність додатку перевірена для різної апаратної і програмної конфігурації. Перелічимо переваги розробленого веб-додатку у порівнянні з аналогами. Новизна полягає у реалізації ефективних механізмів контролю введення інформації, гнучкій локалізації, зручному відображенні збереженої інформації. Розроблений контроль на введення числових покажчиків дозволив розв'язати проблему можливого некоректного введення інформації користувачами. При проходженні аналогічної анкети, створеної в Google Forms, кількість похибок користувачів досягала 9\%. В подальшому додаток можна легко локалізувати за рахунок використання JSON-формату. При використанні онлайн-сервісів для здійснення локалізації потрібно створювати нову форму опитування. В додат- 
ку можна переглядати базу анкет. B Google Forns для перегляду треба використовувати Excel, що створює незручності для користувача і може привести до проблем з сумісністю. Час завантаження додатку - 0.9 с. Аналогічна анкета, створена в Google Forns, завантажується 2,2 с, що на 133\% більше, ніж у розробленого додатку.
У порівнянні з такими сервісами як Survey Monkey, Survio, Simpoll i Anketolog, повні версії яких платні, розроблений застосунок безкоштовний. В подальших дослідженнях планується розширення його функціональності для застосування в інших видах опитування.

\title{
Список літератури
}

1. Dall'Agnol M., Sillitti A., Succi G. Project Management and agile Methodologies: A Survey. International Conference on Extreme Programming and Agile Processes in Software Engineering, 2014. P. 223-226. https://doi.org/10.1007/978-3-54024853-8_28.

2. Azizyan G., Magarian M. K., Kajko-Matsson M. Survey of Agile Tool Usage and Needs. Agile Conference. 2011. P. 29-38. http://dx.doi.org/10.1109/AGILE.2011.30.

3. Mikkelsen M. F. Perceived project complexity: a survey among practitioners of project management. International Journal of Managing Projects in Business. 2021. No. 3(14). P. 680-698. https://doi.org/10.1108/IJMPB-03-2020-0095.

4. Fernando Y., Walters T., Ismail M. N., Seo Y. W., Kaimasu M. Managing project success using project risk and green supply chain management: A survey of automotive industry. International Journal of Managing Projects in Business. 2019. No. 2(11). P. 332-365. https://doi.org/10.1108/IJMPB-01-2017-0007.

5. Martens M. L., Carvalho M. M. Key factors of sustainability in project management context: A survey exploring the project managers perspective. International Journal of Project Management. 2017. Vol. 35(6). P. $1084-1102$. https://doi:10.1016/j.ijproman.2016.04.004.

6. Cuevas G., Serrano A. Assessment of the requirements management process using a two-stage questionnaire. Fourth International Conference on Quality Software. 2004. P. 110-116 https://doi.org/10.1007/978-3-540-75381-0_5.

7. Ivan G., Gonzalo C. C. Determining Practice Achievement in Project Management Using a Two-Phase Questionnaire on Small and Medium Enterprises. European Conference on Software Process Improvement. 2004. P. 110-116. https://doi.org/10.1109/ICSEA.2007.27.

8. Taherdoost H. Validity and reliability of the research instrument; How to test the validation of a questionnaire/survey in a research. International Journal of Academic Research in Management. 2016. Vol. 5. P. 28-36. http://doi.org/10.2139/ssrn.3205040.

9. Ali H., Khan M. Z., Rehman U. An Empirical study on adoption of Agile Project Management Methodology and its effect on Project Success with moderating role of Organizational Culture. European Journal of Social Impact and Circular Economy. 2016. Vol. 2(1). P. 75-99. https://doi.org/10.13135/2704-9906/5158.

10. Kononenko I. V., Lutsenko S. Method for selection of project management approach based on fuzzy concepts. Вісник Національного технічного університету “ХПI”. 2017. № 2. С. 8-17. http://doi: 10.20998/2413-3000.2017.1224.2.

11. Кононенко И. В., Агаи А., Луценко С. Ю. Применение метода синтеза методологии управления проектом при нечетких исходных данных. Восточноевропейский журнал передовых технологий. 2016. № 3(80). С. 32-39. http://doi:10.15587/1729-4061.2016.65671.

12. Kononenko I., Lutsenko S. Application of the Project Management Methodology Formation's Method. Organizacija. 2019. Vol. 52. No. 4. P. 286-308. http://doi:10.2478/orga-2019-0018.

13. Nayak, M. S. D. P., Narayan K. A. Strengths and weakness of online surveys. IOSR Journal of Humanities and Social Science. 2019. Vol. 24(5). P. 31-38. http://doi:10.9790/0837-2405053138.

Надійшла до редколегії 23.07.2021 Схвалена до друку 14.09.2021

\section{Відомості про автора:}

\section{Прочухан Дмитро Володимирович}

викладач Харківського комп'ютерно-технологічного фахового коледжу Національного технічного університету “Харківський політехнічний інститут”, Харків, Україна

https://orcid.org/0000-0002-4622-1015

\author{
Information about the author: \\ Dmitriy Prochukhan \\ Instructor of Kharkiv Computer and Technology \\ Professional College National Technical \\ University "Kharkiv Polytechnic Institute", \\ Kharkiv, Ukraine \\ https://orcid.org/0000-0002-4622-1015
}

\section{РЕАЛИЗАЦИЯ ПРИЛОЖЕНИЯ ПРОВЕДЕНИЯ АНКЕТИРОВАНИЯ ЧЛЕНОВ ПРОЕКТНЫХ КОМАНД}

\author{
Д.В. Прочухан
}

Рассмотрена актуальная проблема обеспечения эффективного механизма анкетирования членов проектньх команд. В результате проведенного анализа публикаций обосновано создание веб-приложения в качестве программного обеспечения для решения приведенной задачи. Программное обеспечение должно устранять недостатки аналогов: неэффективный контроль ввода информации, отсутствие гибкой локализации, сохранение результатов в неудобном формате. Для реализации приложении выбраны средства разработки HTML, CSS, Javascript. Для хранения результатов 
использована система управления базами данных Firebase. Адаптивность разработанного приложения позволяет пользователям проходить анкетирование на разных типах устройств, просматривать итоги опроса, а администраторам - проводить анализ полученной информации, осуществлять настройку внешнего вида анкеть: редактировать параметры и содержание вопросов, добавлять новые вопросы и удалять неактуальные. Реализовано отдельную странииу для просмотра базы данных анкет и итогов опроса, на которой за счет программного сжатия информации обеспечивается удобный просмотр для пользователя. Предусмотрен контроль ввода числовых показателей, обязательный выбор одного правильного ответа в соответствующих вопросах, что обеспечивает разработанному приложению преимущества над аналогами. Программный код оптимизирован для обеспечения минимального времени загрузки приложения - 0.9 с. Обеспечена возможность дальнейшей локализации приложения за счет использования JSON-формата. Работоспособность программного продукта проверена с использованием различной аппаратной и программной конфигурации. Разработанное приложение может быть использовано для проведения анкетирования членов проектных команд, сбора параметров оценки проектов, коллекционирования, обработки результатов, применения в программном обеспечении “PM Guide”. Гибкость архитектуры и программного кода предоставляет возможности использовать программу для проведения других видов опроса в проектном менеджменте.

Ключевые слова: анкетирование, опрос, проектный менеджмент, выбор методологии.

\section{APPLICATION IMPLEMENTATION OF THE QUESTIONNAIRE OF THE PROJECT TEAMS' MEMBERS}

\section{Prochukhan}

The actual problem of ensuring an effective mechanism for surveying members of project teams is considered. A review of the analysis of publications justifies the creation of a web application as a software solution to this task. The software should eliminate the disadvantages of analogues: inefficient input control, lack of flexibility of localization, keeping results in an inconvenient format. HTML, CSS, Javascript development tools were selected for application implementation. The Firebase database management system is used for storing the results. The adaptability of the developed application allows users to go through questionnaires on different types of devices, to view the results of the survey, and administrators to analyze the obtained information, to make adjustments to the appearance of the questionnaire: to edit parameters and content of queries, add new questions and delete irrelevant questions. A separate page has been implemented for viewing the database of questionnaires and survey results, on which the software compression of information provides user-friendly viewing. Control of numerical input, mandatory selection of one correct answer in the appropriate questions, that give the developed application advantages, are provided. The software code is optimized to provide a minimum application loading time of 0.9 s. It is possible to further localize the application by using JSON-format. The workability of the software is tested, using different hardware and program configuration. The developed application can be used for conducting questionnaires of members of project commands, collecting parameters of project evaluation, collecting, processing results, application in software "PM Guide". The flexibility of the architecture and software code provides opportunities to use the program to conduct other types of surveys in project management.

Keywords: questionnaire, survey, project management, selection of methodology. 